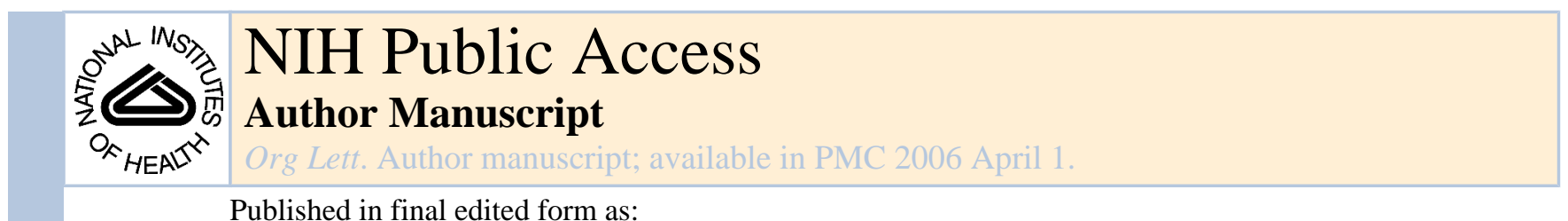

Published in final edited form as:

Org Lett. 2004 November 25; 6(24): 4567-4569.

\title{
Synthesis of Rigid Multivalent Scaffolds Based on Adamantane
}

\author{
Wolfgang Maison* ${ }^{\star}$, John V. Frangioni ${ }^{\star}$, and Nadine Pannier ${ }^{\dagger}$ \\ Universität Hamburg, Institut für Organische Chemie, Martin-Luther-King-Platz 6, 20146 Hamburg, \\ Germany, and Harvard Medical School, Beth Israel Deaconess Medical Center, SL-B05, 330 \\ Brookline Avenue, Boston, Massachusetts 02215
}

\section{Abstract}

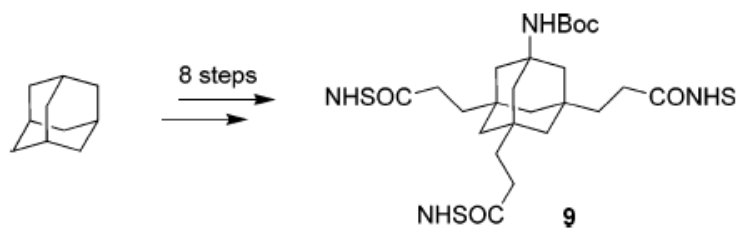

An efficient route to novel 1,3,5,7-

tetrasubstituted derivatives of adamantane is described. This route starts from adamantane and gives the tetrafunctionalized derivative 9 in eight steps with an overall yield of $23 \%$. These tetrahedrally shaped molecules possess three identical arms terminated by an activated carboxylic acid derivative and a protected amino function in the 1-position. We propose these tetravalent cage compounds such as 9 as scaffolds for the assembly of ligand/marker conjugates for studies of multivalent ligand receptor interactions.

Derivatives of adamantane have found numerous applications in medicinal chemistry ${ }^{1}$ and material science. ${ }^{2}$ Especially for the latter applications, tetrasubstituted adamantanes are valuable scaffolds because they are mechanically rigid and conformationally well defined. These special features of the adamantane core attracted our interest for studies on multivalent ligand/receptor interactions. We have been interested in the synthesis of small molecule cancer specific ligands for a while ${ }^{3}$ and would like to use adamantane derivatives as scaffolds for multivalent tumor targeting.

For this purpose we designed tetravalent adamantane derivatives such as I (Figure 1) with three identical arms A for attachment of linker moieties in the 3,5,7-positions and a fourth functional group B in the 1-position for conjugation to reporter molecules. The adamantane core would thus serve as a rigid building block orienting four arms tetrahedrally in space.

For differential attachment of ligands and markers to the adamantane core we favor amide linkages and were thus aiming for the introduction of carboxylic acids in residues $\mathrm{A}$ and an amine function in residue B in compounds of the general structure I (Figure 1).

The most obvious two retrosynthetic routes A and B are shown in Figure 1. In route A the substitution pattern in target compound $\mathbf{I}$ is derived from an already differentially substituted adamantane derivative. A suitable precursor is tribromoadamantane that is readily available by bromination of adamantane.

maison@chemie.uni-hamburg.de.

†Universität Hamburg.

†Harvard Medical School.

Supporting Information Available: Full experimental details and data for characterization and ${ }^{1} \mathrm{H}$ NMR and ${ }^{13} \mathrm{C}$ NMR spectra for new compounds 3-9. This material is available free of charge via the Internet at http://pubs.acs.org. 
Central intermediate of route B is a symmetrically tetrasubstituted adamantane derivative that would have to be desymmetrized for example by monoesterification of adamantane tetracarboxylic acid. Route B, however, has significant drawbacks regardless of starting from tetrahaloadamantanes or adamantane tetracarboxylic acid as an intermediate. 1,3,5,7Tetrahaloadamantanes are easy to synthesize from adamantane ${ }^{4}$ but quite difficult to functionalize because of low solubility and reactivity. ${ }^{5}$ On the other hand 1,3,5,7-adamantane tetracarboxylic acid is difficult to synthesize in the multigram quantities that are needed for our studies. ${ }^{6}$ In consequence we focused on route $\mathrm{A}$ as a suitable approach.

Adapting a route of Malik and co-workers, ${ }^{7}$ we synthesized triethynyladamantane $\mathbf{2}$ in two steps from adamantane for two reasons. First, compound $\mathbf{2}$ should allow introduction of carboxylic acid functionalities for construction of residues A in Figure 1, and second, it should also allow a variation in spacer length between the adamantane core and the carboxylic acids. Compound $\mathbf{2}$ is thus a key intermediate in our synthetic protocol.

We have synthesized tribromoadamantane $\mathbf{1}$ according to a method of Delimarskii ${ }^{8}$ rather than the procedure of Stetter and Wulff ${ }^{9}$ or Malik and co-workers ${ }^{7}$ since the latter always gave a significant amount of 1,3-dibromoadamantane.

Tribromide 1 was then treated with vinyl bromide and $\mathrm{AlCl}_{3}$, and the resulting bromoalkane (not shown) was submitted as a crude product to elimination with ${ }^{t} \mathrm{BuOK}$ to give triethynyladamantane $\mathbf{2}$ in good yield. Both compounds, $\mathbf{1}$ and $\mathbf{2}$, can be prepared on a large scale, since they are easy to purify by crystallization or distillation, respectively.

Alkyne $\mathbf{2}$ is a key intermediate in our synthetic scheme because it can be modified along various routes. In a first attempt to prove our synthetic concept, alkyne $\mathbf{2}$ was converted to carboxylic acid $\mathbf{3}$ in excellent yield by formation of a lithium acetylide and subsequent quenching with carbon dioxide (Scheme 2). Hydrogenation of the alkyne functions gives the trisubstituted adamantane derivative $\mathbf{4}$ almost quantitatively. Again both compounds, 3 and $\mathbf{4}$, are readily purified by crystallization from acetonitrile.

Introduction of an amine in the remaining free bridgehead position in $\mathbf{4}$ was planned via a twostep procedure of bromination and a subsequent Ritter reaction with acetonitrile. Both reactions are well-known for bridgehead manipulations at the adamantane scaffold but are sometimes troublesome for substituted adamantane derivatives. ${ }^{10}$

Because brominations of adamantane are often performed under harsh conditions ${ }^{9}$ (a notable exception is the phase transfer catalytic concept ${ }^{11}$ ), we suspected that bridgehead bromination of trisubstituted adamantane $\mathbf{4}$ could be accompanied by R-bromination of its carboxylic acids. Initial attempts to brominate $\mathbf{4}$ in pure bromine or with bromine and different Lewis acids $\left(\mathrm{AlCl}_{3}, \mathrm{AlBr}_{3}, \mathrm{BBr}_{3}\right)$ all resulted in either complex reaction mixtures resulting from polybromination or no conversion of starting material (for pure bromine). Again, iron in bromine and careful control of reaction conditions $\left(0{ }^{\circ} \mathrm{C}\right.$ for $\left.12 \mathrm{~h}\right)$ was the method of choice. As outlined in Scheme 3, tricarboxylic acid $\mathbf{4}$ was thus converted to tetrasubstituted adamantane 5 in good yield. Ritter reaction of bromide 5 proceeded smoothly using nitronium tetrafluoroborate following a protocol from Bach and co-workers. ${ }^{12}$ The tetrasubstituted adamantane $\mathbf{6}$ with an $N$-acetylated amino function in the 1-position was thus synthesized in fair yield over two steps from precursor 4 .

It turned out later that compound $\mathbf{6}$ can be prepared even more efficiently in one step using a procedure of Khil'chevskii and co-workers. ${ }^{13}$ Following this protocol, compound $\mathbf{4}$ was heated for $24 \mathrm{~h}$ in a mixture of bromine, water, and acetonitrile. Bridgehead bromination and Ritter reaction with acetonitrile occurred in one pot and gave tetrasubstituted adamantane $\mathbf{6}$ in good yield along with bromide $\mathbf{5}$ as the only defined byproduct (9\%) of this reaction. 
A second protocol for a one-step conversion of adamantane derivatives to $\mathrm{N}$-acetamides via a bromine free amidation ${ }^{15}$ failed to give tetrafunctionalized adamantane $\mathbf{6}$, and only a complex mixture of reaction products was isolated.

The $N$-acetyl group in amide $\mathbf{6}$ can be removed by acidic hydrolysis of the acetamide in refluxing aqueous $\mathrm{HCl}^{14}$ to give the free amine 7 as its hydrochloride salt. Loss of the amine function under acidic conditions and substitution with chlorine has been reported for alkylsubstituted amino-adamantanes in the literature. ${ }^{15}$ However, for the conversion of amide 6 to amine 7 we were not able to detect any substitution of the amine function by chlorine during acidic hydrolysis. Amino acid $\mathbf{7}$ is well soluble in water at acidic $\mathrm{pH}$, and all impurifications were thus removed by washing the acidic aqueous reaction mixture with ethyl acetate.

Using a standard protocol, ${ }^{16}$ amino acid 7 was Boc-protected with $\mathrm{Boc}_{2} \mathrm{O}$ in alkaline aqueous solution to give $\mathrm{N}$-terminally protected $\mathbf{8}$ in moderate yield. In a last step the carboxylic acids of 8 were converted to NHS-esters under standard conditions ${ }^{17}$ with $N$-hydroxy succinimide and DCC to give tetravalent adamantane $\mathbf{9}$ in good yield after purification by crystallization from 2-propanol. We prefer NHS-ester for activation of carboxylic acids in $\mathbf{9}$ because they should permit coupling of the adamantane scaffold to ligands in aqueous media. ${ }^{18}$

In summary, we have realized the synthesis of a tetravalent adamantane derivative 9 in eight steps with $23 \%$ overall yield. Compound $\mathbf{9}$ has three NHS-esters for coupling to ligands and a protected amine for conjugation to a reporter group. A key intermediate in our sequence is triethynyl adamantane 2 . Starting from this versatile intermediate, it should be possible to synthesize a number of analogues to $\mathbf{9}$ with different spacers between the adamantane core and the carboxylic acids. We will use these scaffolds for studies of multivalent receptor/ligand interactions.

\section{Supplementary Material}

Refer to Web version on PubMed Central for supplementary material.

\section{Acknowledgements}

W.M. is supported by Deutsche Forschungsgemeinschaft grant MA-2529/1 and Fonds der Chemischen Industrie. J.V.F. is supported by grants R21/R33-CA-88245 and R21-CA-88870 from the National Institutes of Health (National Cancer Institute). We thank Prof. Daniel S. Kemp for helpful suggestions.

\section{References}

1. a Henkel JG, Hane JT, Gianutsos G. J Med Chem 1982;25:51-56. [PubMed: 7086822] b Zah J, Terre'Blanche G, Erasmus E, Malan SF. Bioorg Med Chem 2003;11:3569-3578. [PubMed: 12901901]

2. For some recent applications, see: (a) LiQJinCPetukhovPARukavishnikovAVZaikovaTOPhadkeALaMunyonDHLeeMDKeanaJFJ Org Chem20046910101019 [PubMed: 14961648] b Li Q, Rukavishnikov AV, Petukhov PA, Zaikova TO, Jin C, Keana JFW. J Org Chem 2003;68:4862-4869. [PubMed: 12790592] c Radhakrishnan U, Schweiger M, Stang PJ. Org Lett 2001;3:3141-3143. [PubMed: 11574015]

3. Maison W, Grohs DC, Prenzel AHGP. Eur J Org Chem 2004:1527-1543.

4. Sollott GP, Gilbert EE. J Org Chem 1980;45:5405-5408.

5. An exception is arylation by a Friedel-Crafts-type reaction (NewmanHSynthesis1972692693and cyanation by a photochemical conversion (LeeGSBasharaJNSabihGOganesyanAGodjoianGDuongHMMarinezERGutierrezCGOrg Lett2004617051707 [PubMed: 15151394]

6. Bashir-Hashemi A, Li J, Gelber N. Tetrahedron Lett 1995;36:1233-1236. 
7. Malik AA, Archibald TG, Baum K, Unroe MR. J Polym Sci, Part A: Polym Chem 1992;30:17471754.

8. Delimarskii RE, Rodionov VN, Yurchenko AG. Ukr Khim Zh 1988;54:437-438.

9. Stetter H, Wulff C. Chem Ber 1960;93:1366-1371.

10. a Fort RC, v Schleyer PR. Chem Rev 1964;64:277-300. b Moiseev IK, Makarova NV, Zemtsova MN. Russ Chem Rev 1999;68:1001-1020.

11. Schreiner PR, Fokin AA, Lauenstein O, Okamoto Y, Wakita T, Rinderspacher C, Robinson GH, Vohs JK, Campana CF. J Am Chem Soc 2002;124:13348-13349. [PubMed: 12418863]

12. a Bach RD, Holubka JW, Taaffee TA. J Org Chem 1979;44:1739-1740. b Olah GA, Gupta BG, Balaram BG, Narang SC. Synthesis 1979:274-276.

13. Khil'chevskii AN, Baklan VF, Kukhar VP. Zh Org Khim 1996;32:1022-1024.

14. Stepanov FN, Srebrodol'skii YI. J Org Chem USSR 1966;2:1612-1615.

15. Novikov SS, Khardin AP, Butenko LN, Kulev IA, Novakov IA, Radchenko SS, Burdenko SS. Zh Org Khim 1980;16:1433-1435.

16. Gee KR, Nin L, Schaper K, Hess GP. J Org Chem 1995;60:4260-4263.

17. Anderson GW, Zimmerman JE, Callahan FM. J Am Chem Soc 1963;85:3039.

18. Zaheer A, Wheat TE, Frangioni JV. Mol Imaging 2002;1:354-364. [PubMed: 12926231] 


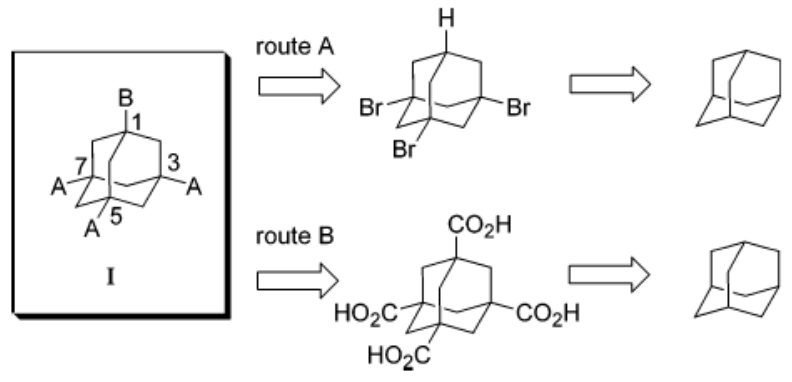

Figure 1.

Retrosynthetic analysis of adamantane derivatives I. 


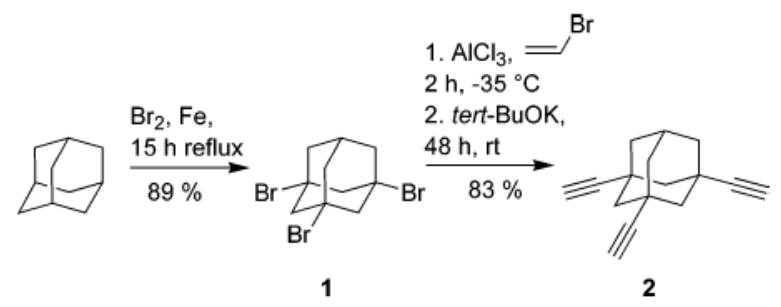

Scheme 1.

Org Lett. Author manuscript; available in PMC 2006 April 1. 


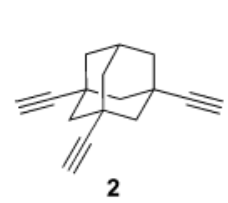

1. MeLi, THF, $0^{\circ} \mathrm{C}$

2. $\mathrm{CO}_{2},-70^{\circ} \mathrm{C}$

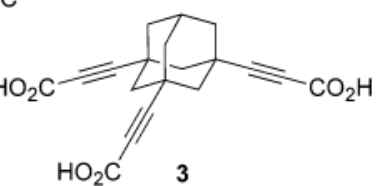

$99 \% \quad 10 \% \mathrm{Pd} / \mathrm{C}, 1 \mathrm{~atm} \mathrm{H}_{2}$ $\checkmark \mathrm{THF}, 48 \mathrm{~h}, \mathrm{rt}$

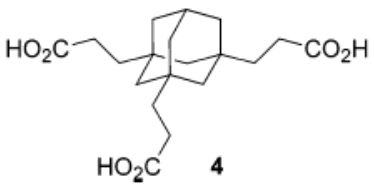

Scheme 2.

Org Lett. Author manuscript; available in PMC 2006 April 1. 


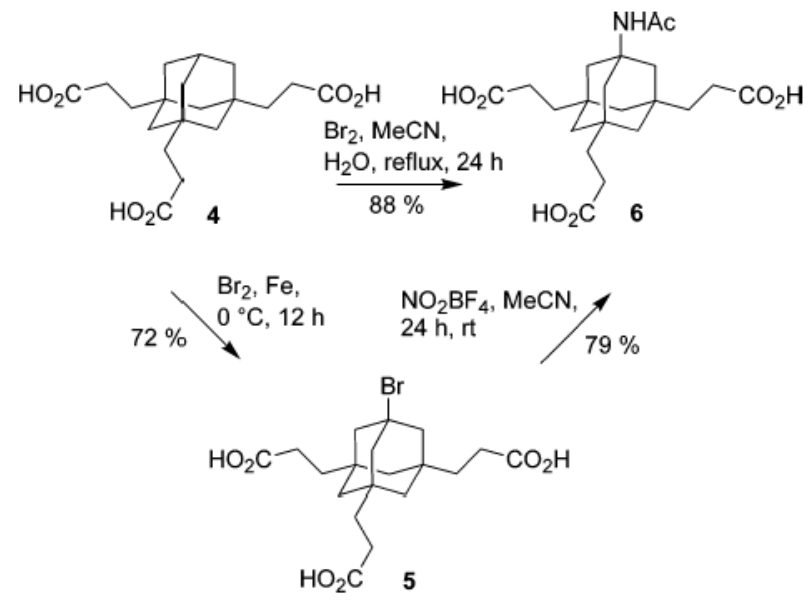

Scheme 3.

Org Lett. Author manuscript; available in PMC 2006 April 1. 

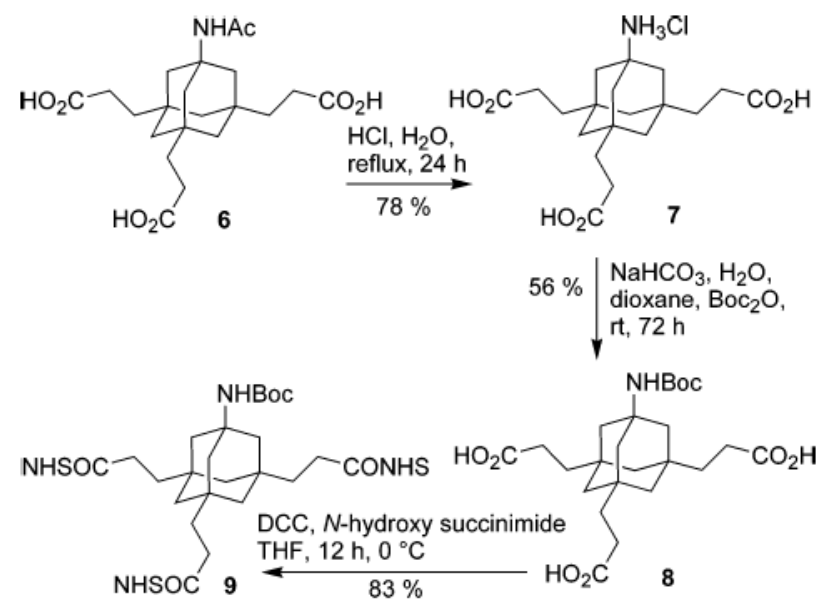

Scheme 4.

Org Lett. Author manuscript; available in PMC 2006 April 1. 